\title{
SCAPULAR FRACTURES IN BLUNT CHEST TRAUMA - SELF-EXPERIENCE STUDY
}

\author{
Iv. Novakov ${ }^{*}$, N. Traykova ${ }^{2}$, L. Tchervenkov ${ }^{2}$ \\ ${ }^{1}$ Department of Special Surgery, Medical University, Plovdiv, Bulgaria \\ ${ }^{2}$ Department of Roentgenology and Radiology, Medical University, Plovdiv, Bulgaria
}

\begin{abstract}
PURPOSE. The aim of this retrospective study was to report the scapular fractures in patients with blunt chest trauma and to present the type and the frequency of associated thoracic injuries. METHODS. Nine patients with fractures of the scapula were included in the study. The mechanisms of the injury, the type of scapular fractures and associated thoracic injuries were analyzed. RESULTS. Scapular fractures were caused by high energy blunt chest trauma. Body of the scapula was fractured in all scapular fractures. In all cases scapular fractures were associated with other thoracic injuries (average 3,25/per case). Rib fractures were present in eight patients, fractured clavicula - in four cases, affection of pleural cavity - in eight of the patients and pulmonary contusion in all nine cases. Eight patients were discharged from the hospital up to the $15^{\text {th }}$ day. One patient had died on the $3^{\text {rd }}$ day because of postcontusional lung edema. CONCLUSIONS. The study confirms the role of scapular fractures as a marker for the severity of the chest trauma (based on the number of associated thoracic injuries), but doesn't present scapular fractures as an indicator for high mortality in blunt chest trauma patients.
\end{abstract}

Key words: fractured scapula, thoracic trauma, associated injuries, rib fractures, pulmonary contusion

\section{INTRODUCTION}

Scapular fractures are one of the most unusual bony fractures in hospitalized patients. Mainly, they are result from the major direct trauma to the thorax, such as motor vehicle accidents, falls from heights and crushing injuries (1-6). The importance of the scapular fractures in blunt chest trauma lies not just in the injury of the scapula but in the close association with other thoracic injuries (associated injuries), some of them being life-threatening.

\section{OBJECTIVE}

The aim of this retrospective study was to report on scapular fractures in blunt chest trauma patients and to present the type and the frequency of associated thoracic injuries.

\section{MATERIAL AND METHODS}

Nine patients (eight men and one woman) with fractures of the scapula, hospitalized at Department of Thoracic Surgery, Medical University - Plovdiv from June 2013 to August 2015, were included in this study. The age of the patients ranged from 32 to 72 years

\footnotetext{
*Correspondence to: Ivan Petkov Novakov, Department of Special Surgery, Medical University, Plovdiv, 66 "Peshtersko shosse" str., Plovdiv4004; E-mail: inovakov2003@yahoo.com
}

(mean - 49,3 /SD - 14,6 years). The injury mechanisms, fracture type of scapula and associated thoracic injuries were analyzed.

Computed tomography (CT) examination of the thorax was performed in all nine patients at the time of their admission, in six of them in combination with 3D CT reconstruction. Conventional chest radiograph examinations were used to follow the patients 'conditions. The treatment results weren't the subject of this study.

\section{RESULTS}

Mechanism blunt chest trauma of injury in eight of patients was motor vehicle accident: car accident - two cases; motorcycle accident - four cases; ATV (all-terrain vehicles) accident - one patient and one patient as a pedestrian (Table 1). One patient was injured by severe assault.

The total number of scapular fractures was eleven as two of patients (motorcyclist and pedestrian) had fractures on both scapulas (Figure 1). There were six fractures on the right scapula and five fractures on the left scapula. In all the eleven scapular fractures the body of the scapula was fractured. Fractures of the acromion were established in two of the cases; scapular spine fractures - in two cases, and fracture of the glenoid (glenoid rim) - in one case. 
Table 1. Case summary of the reported nine patients.

\begin{tabular}{|c|c|c|c|c|c|c|c|}
\hline \multicolumn{8}{|c|}{ (m-man; f- female; fr - fracture; $\mathrm{n}$ - case number) } \\
\hline $\mathbf{n}$ & $\begin{array}{c}\text { age } \\
(\text { years })\end{array}$ & gender & $\begin{array}{c}\text { injury } \\
\text { mechanism }\end{array}$ & $\begin{array}{l}\text { side of scapular } \\
\text { fracture }\end{array}$ & $\begin{array}{l}\text { type of scapular } \\
\text { fracture }\end{array}$ & $\begin{array}{l}\text { associated } \\
\text { injuries }\end{array}$ & $\begin{array}{c}\text { stay } \\
\text { (in days) }\end{array}$ \\
\hline 1 & 34 & $\mathrm{~m}$ & car accident & right & body & right clavicula fr.; lung contusion - right & 5 \\
\hline 2 & 51 & $\mathrm{~m}$ & motorcycle & right & body & ribs fr. $-2-4^{\text {th }}$ right; lung contusion - right & 10 \\
\hline 3 & 68 & $\mathrm{~m}$ & motorcycle & left & body; acromion & $\begin{array}{l}\text { ribs fr. }-7-10^{\text {th }} \text { left; lung contusion- left; } \\
\text { haemothorax - left }\end{array}$ & 5 \\
\hline 4 & 49 & $\mathrm{f}$ & pedestrian & bilateral & $\begin{array}{l}\text { right: body } \\
\text { left: body }\end{array}$ & $\begin{array}{l}\text { ribs fr.: } 4-8^{\text {th }} \text { left; haemothorax - right; } \\
\text { haemopneumothorax left; lung contusion - bilateral }\end{array}$ & 8 \\
\hline 5 & 72 & $\mathrm{~m}$ & assault & left & body & $\begin{array}{l}\text { ribs fr.: } 5-10^{\text {th }} \text { left; } \\
\text { left clavicula fr.; haemopneumothorax - left; lung } \\
\text { contusion - left }\end{array}$ & $\begin{array}{c}3 \\
(\text { death })\end{array}$ \\
\hline 6 & 50 & $\mathrm{~m}$ & motorcycle & right & body; glenoid & $\begin{array}{l}\text { ribs fr.: } 1^{\text {st }}, 3-10^{\text {th }} \text { right; } 12^{\text {th }} \text { left; clavicula fr.- right; } \\
\text { Th4 and Th5- spinous processes fr.; } \\
\text { haemopneumothorax - right; } \\
\text { lung contusion - bilateral }\end{array}$ & 11 \\
\hline 7 & 55 & $\mathrm{~m}$ & car accident & left & $\begin{array}{l}\text { body; spine; } \\
\text { acromion }\end{array}$ & $\begin{array}{l}\text { ribs fr.: } 4-11^{\text {th }} \text { left; Th10- body fr.; } \\
\text { haemopneumothorax - left; lung contusion - left }\end{array}$ & 10 \\
\hline 8 & 33 & $\mathrm{~m}$ & motorcycle & bilateral & $\begin{array}{l}\text { right: body } \\
\text { left: body; spine }\end{array}$ & $\begin{array}{l}\text { ribs fr.: } 4-6^{\text {th }} \text { left, } 6^{\text {th }} \text { right; haemothorax }- \text { left; } \\
\text { pneumothorax - right; lung contusion - bilateral }\end{array}$ & 15 \\
\hline 9 & 32 & $\mathrm{~m}$ & atv accident & right & body & $\begin{array}{l}\text { clavicula fr.- right; ribs fr. - } 1^{\text {st }} \text { rib right; } \\
\text { pneumothorax - right; lung contusion - right }\end{array}$ & 13 \\
\hline
\end{tabular}


None of the reported cases of blunt chest trauma had isolated scapular fractures (table 1). In all cases scapular fractures were

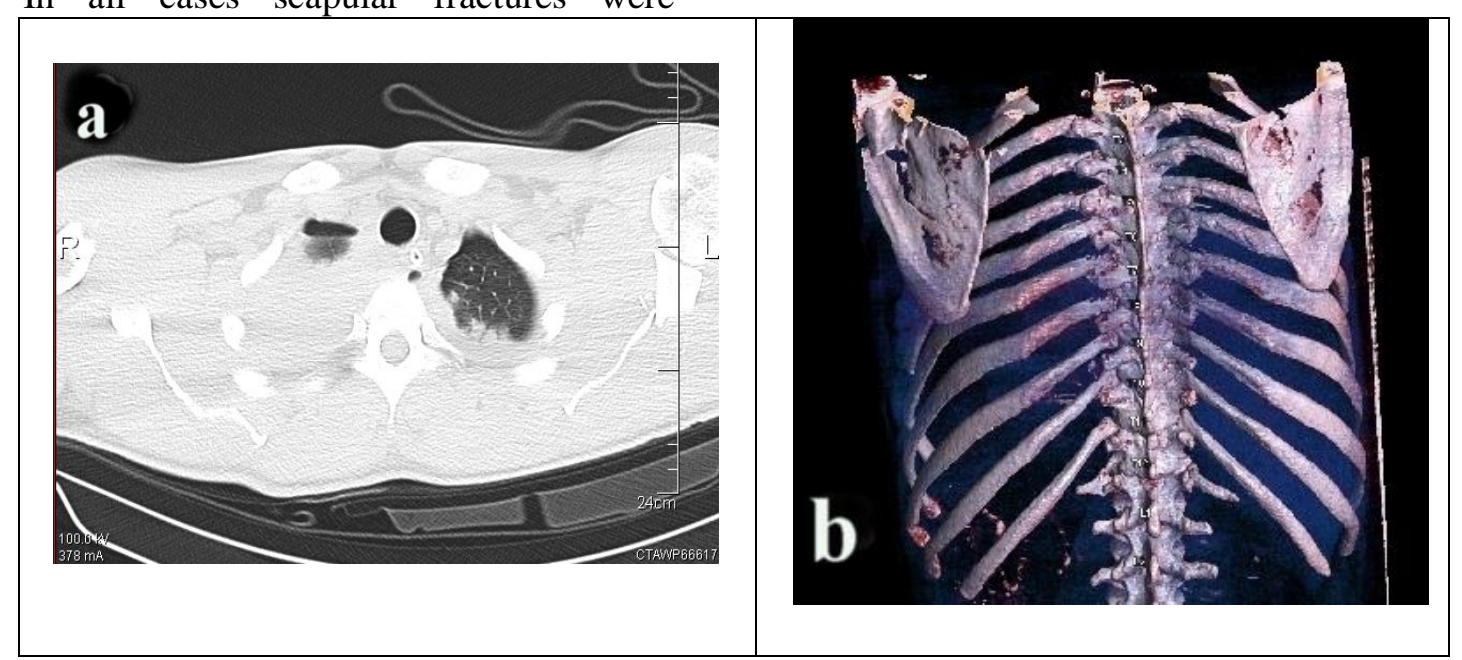

Figure 1. Patients 8: a - axial computed thomography showing: bilateral scapular fractures, bilateral pulmonary contusion, left haemothorax, right pneumothorax; $\mathbf{b}-3 \mathrm{D}$ computed tomography reconstruction showing bilateral scapular body fractures.

Associated chest bone fractures were established in all patients. Rib fractures were seen in eight patients - ipsilateral fractures in all eight patients and in one of them (with right scalular fracture) additionally fracture of the contralateral left $12^{\text {th }}$ rib (Table 1). Multiple rib fractures (3 or more fractured ribs) were established in seven of patients. The fracture of the first rib was present in two patients (Figures 2, 3) - on the inpsilateral side. Four of the patients had ipsilateral fractures of the clavicula (Figures 2, 3). Fractures of the thoracic spine were seen in two patients (one with fracture of posterior part of the body of Th10-vertebra, one with fractures of spinous processes of the Th4 and Th5-vertebra), none of whom had neurological damage (Figure 3).

Pulmonary contusion was established in all of the patients (bilateral in two cases)/ (Table 1). Ipsilateral pleural cavity was affected in eight

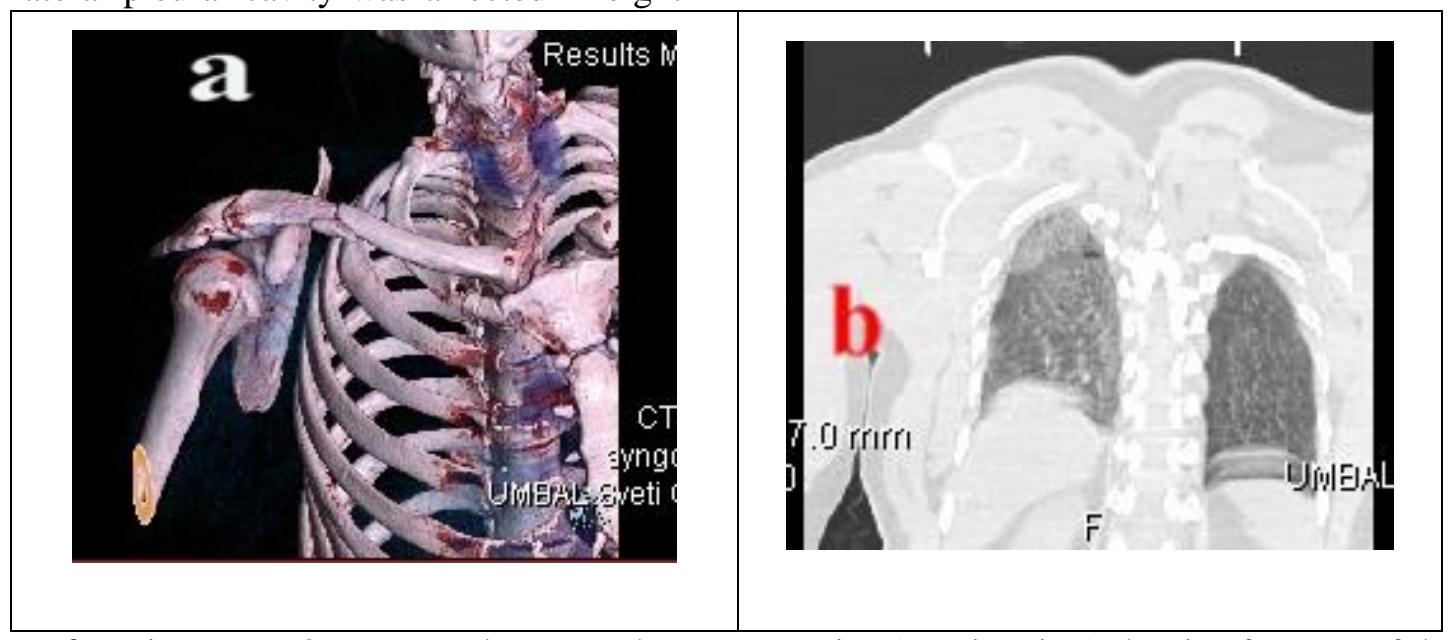

Figure 2. Patient 9: a - 3D computed tomography reconstruction (anterior view) showing fractures of the right clavicula and the first rib; $\mathbf{b}$ - sagittal computed tomography showing right pneumothorax and lung contusion. 


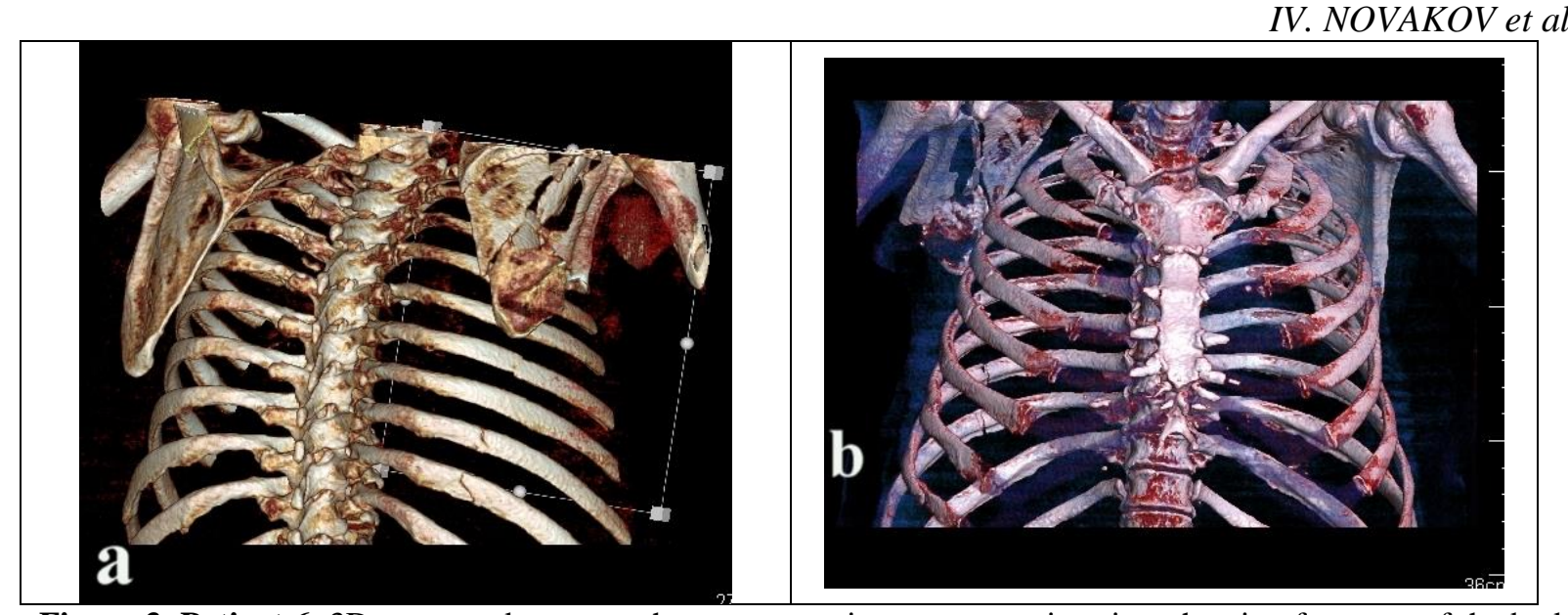

Figure 3. Patient 6. 3D computed tomography reconstruction: a - posterior view showing fractures of the body of the right scapula and Th4, Th5 spinous processes fractures; $\mathbf{b}$ - anterior view showing right clavicula and first rib fractures.

\section{DISCUSSION}

Scapular fractures are uncommon (accounting for only $0,4-1 \%$ of all bone fractures and 3 to $5 \%$ of all shoulder girdle injuries) due to the muscular coverage of the scapula and as a rule they are result of marked force applied in the course of high-velocity chest trauma (7). According to the literature data, 32 to $80 \%$ of scapular fractures are a result from traffic accidents (2, 3, 6-8). We report road accidents to be the cause of $88,7 \%$ of the scapular fractures and confirm that fractures of the scapula have a huge impact on the thoracic cage.

Other publications claim that patients with scapular fractures are predominately male gender, an average age of 35 years (range, 2550 years) / (6-10). Our patient population's average age of 44 years and range of 32-72 years, with only one woman, are similar to the data reported in the literature. The age and sex distribution in the frequency of the scapular fractures can be explained by differences in behavior and physical activity.

Several authors have presented the sequence of the scapular fractures in declining order: fractures of the scapular body followed by those of scapular neck, glenoid, acromion and coracoid process of the scapula $(1,5,6,11)$. Because of the relatively small number of patients, we couldn't present a declining order in frequency of type of scapular fractures. The type of scapular fractures, according to the affected part of the scapula depends on the mechanism of trauma - direct or indirect. It is a rule that direct blunt chest trauma leads to fractures of the scapular body, spine, or the acromion. Indirect trauma that pulls the arm or compresses the shoulder causes fracture of the scapular neck and/or glenoid. Our reported patients were exposed to direct chest trauma.
That explains why the body of the scapula was broken in all of the reported nine cases, as well as why the glenoid was fractured only in one case and there were no fractures of the scapular neck.

Although the treatment isn't a subject of this study, we notice that scapular body fractures, irrespective of the number of the fragments, usually are managed non-operatively, with favorable results. Conservative treatment was successfully applied to all of our patients, with pain relief medication and only in one case shoulder immobilization.

Two of our patients had bilateral scapular fractures. These were cases with severe direct high-energy impact on the thoracic cage. According to the data in the literature bilateral scapular fracture is a very rare injury complex (12-16). We found published several single case reports and only one study with reported six cases with bilateral scapular fractures. Two mechanisms of bilateral scapular fractures were described: by direct violence (as in our cases) or by muscle spasms due to epileptic seizure or electrical shock. It is expected that the increasing of the number of chest trauma patients with high-energy impact will increase the potential for bilateral scapular fractures.

Isolated fractures of the scapula are very rare and they are usually treated in the outpatient clinics. In contrast with the isolated scapular fractures, these with other associated thoracic injuries are admitted to the hospital, as we managed with the reported nine cases. Associated thoracic injuries determine the importance of the scapular fractures, being an indicator to the severity of blunt chest trauma $(2,3)$. We report the number of associated injuries of 3,25/per case, that are similar to the other published data. At this point, we confirm 
the scapular fractures as a marker of the severity of the chest trauma.

The review of the literature established rib fractures as the most common associated chest injury in patients with fractured scapula. We reported $88,9 \%$ fractured ribs and confirmed that damaged ipsilateral ribs in the lower thoracic cage are more frequent since they are relatively less protected there. The injury complex fractures of the scapula and the first rib is quite rare. It is a rule, that fractures of the first rib require high energy injuries due to its profound location and good protection by overlying soft tissues, clavicle and scapula (12, $17,18)$. In cases with injury complex scapular and first rib fractures there is a high risk of other thoracic injuries like injury of subclavian artery, brachial plexus injury, rupture of the apex of the lung, pneumothorax. Our reported two cases had no injury of the subclavian artery and neurological deficiency. We established pleural involvement, without knowing the right cause of the pleural injury: fracture of the first rib or fracture of another chest bone.

In a declining order, we found that clavicular fractures were the second type of associated chest bone fractures. We established that the clavicula was broken in its lateral third, close to the shoulder joint, which can be explained by the direction of the impact to the shoulder girdle. As in cases with first rib fractures, there was a similar risk of injury of subclavian artery, brachial plexus, as well as rupture of the apex of the lung. Fortunately, only pleural injury was established in three of our reported cases with associated clavicular fractures.

We reported associated pleural injuries (pneumothorax, haemothorax and haemopneumothorax) in $66,7 \%$ of the cases with scapular fractures. Although the review of the literature established rib fractures as the most common associated chest injury, we found that pulmonary contusion was present in $100 \%$ of the reported patients. We explain that to be a result of severe mechanical impact on the thoracic cage. The severity of lung contusion was determined on the base of the result of imagine methods (chest X-ray and CT) but this wasn't the subject of this study. Pulmonary contusion, with postcontusional lung edema, is considered as the most common cause for the death in hospitalized blunt thoracic trauma patients that was found in the only death case we report. The mortality in scapular fractures in our study was lower than the one reported in the literature. Therefore the results of our study allow us to conclude that scapular fractures

\section{NOVAKOV et al.}

couldn't be accepted as a marker of the mortality in blunt chest trauma patients.

\section{CONCLUSIONS}

This retrospective study presents one of the relatively rare injuries in blunt chest trauma patients - scapular fractures. The study presents the effects of direct high energy impact on the thoracic cage: (1) causing of fractures of the scapular body and (2) causing of other associated thoracic injuries, which are more common - pulmonary contusion. The study confirms the role of scapular fractures as a marker of the severity of the chest trauma (based on the number of associated thoracic injuries), but doesn't present scapular fractures as an indicator of high mortality in blunt chest trauma patients.

\section{REFERENCES}

1. Neuhaus V, Bot AG, Guitton GT et al. Scapular fractures: interobserver reliability of classification and treatment. J Orthop Trauma; 3:124-129, 2014.

2. Thompson DA, Flynn TC, Miller PW et al. The significance of scapular fractures. $J$ Trauma; 10:974-977, 1985.

3. Stephens NG, Morgan AS, Corvo P et al. Significance of scapular fracture in blunttruma patient. Ann Emerg Med ; 4:439-442, 1995.

4. Collins JI. Chest wall trauma. J Thorac Imaging; 2:112-119, 2000.

5. Harris RD, Harris JH. The prevalence and significance of missed scapular fractures in blunt chest trauma. Am J Roentgenol.; 4:747750, 1988

6. Armstrong CP, Spuy JV. The fractured scapula: importance and management based on a series of 62 patients. Injury; 15: 324-329, 1984.

7. Gosens T, Speigner B, Minekus J. Fracture of the scapular body: functional outcome after conservative treatment. $J$ Shoulder Elbow Surg; 18:443-448, 2009.

8. Schofer MD, Sehrt AC, Timmesfeld N et al. Fractures of the scapula: long-term results after conservative treatment. Arch Orthop Trauma Surg; 129:1511-1519, 2009.

9. Lantry JM, Roberts CS, Giannoudis PV. Operative treatment of scapular fractures: a systematic review. Injury Int J Care Injured; 39: 271-283, 2008.

10. Cole PA. Scapular fractures. Orthop Clin North Am; 33:1-18, 2002.

11. Scarano JL, Richardson M, Taylor JA. Comminuted scapular body fractures: a report of three cases managed conservatively in chiropractic settings. J Can Chiropr Assoc; 57:176-184, 2013. 
12. Gulbahar G, Kaplan T, Turket HB et al. A rare entity: bilateral first rib fractures accompanying bilateral scapular fractures. Case Report in Emerg Med;1: 1-3, 2015.

13. Tucek M, Bartonicek J, Novotny P et al. Bilateral scapular fractures in adults. Intern Orthop; 37:659-665, 2013.

14. Christofi T, Raptis DA, Kankate RK. Low-energy bilateral scapular fractures. Emerg Med J; 25: 501-506, 2008.

\section{NOVAKOV et al.}

15. Kotak BP, Haddo O, Iqbal M. et al. Bilateral scapular fractures after electrocution. J R Soc Med; 93:143-144, 2000.

16. Dumas JL, Walker N. Bilateral scapular fractures secondary to electric shock. Arch Orthop Trauma Surg; 111:287-288, 1992.

17. Chatterjee S, Dey R, Guha P. et al. Isolated traumatic bilateral firs rib fractures: a rare entity. Tanaffos; 4:60-63, 2011.

18. Dwivedi SC, Varma AN. Bilateral fractures of the first ribs. J Trauma; 23:538540, 1983. 